\title{
Diffuse Lipomatosis
}

National Cancer Institute

\section{Source}

National Cancer Institute. Diffuse Lipomatosis. NCI Thesaurus. Code C6504.

A neoplastic process characterized by a diffuse poorly circumscribed overgrowth of adipose tissue. It has been associated with several genetic disorders and different clinical conditions such as liver disease, excessive alcohol intake, adrenocortical steroid therapy, and antiretroviral therapy. 